\title{
Adopting Instructional Strategies for English Language Learners in Elementary Classrooms
}

\author{
Jiji Olds ${ }^{1}$, Michelle McCraney ${ }^{1}$, Sunddip Panesar-Aguilar ${ }^{2, *} \&$ Chris Cale $^{3}$ \\ ${ }^{1}$ School of Education, Walden University, Minneapolis, Minnesota, United States \\ ${ }^{2}$ College of Health Sciences, University of St. Augustine, Florida, United States \\ ${ }^{3}$ School of Education, Northcentral University, California, United States \\ *Correspondence: College of Health Sciences, University of St. Augustine, St. Augustine, FL, United States. Tel: 1- \\ 904-770-3676. E-mail: saguilar@usa.edu
}

Received: March 4, 2021

Accepted: May 28, $2021 \quad$ Online Published: June 12, 2021

doi:10.5430/wje.v11n3p18

URL: https://doi.org/10.5430/wje.v11n3p18

\begin{abstract}
In an Eastern U.S. school district, little is understood about how elementary general education teachers apply instructional strategies for English Language Learners (ELLs) in the classroom and which strategies they perceive support academic achievement. The purpose of this basic qualitative study was to explore elementary general education teachers' reported application of ELL instructional strategies and their perceptions of how those strategies support ELL academic achievement. The study's conceptual framework consisted of Vygotsky's sociocultural theory, which infers that learning is a social process guided by interactions with one's environment, people, and culture. Also framing this study was Krashan's second language acquisition theory (Long, 1983), which infers that language is attained though one's strong desire to interact with the world around them. Two research questions were used to investigate the reported ELL instructional strategies used by teachers and how teachers perceive those strategies support ELLs' achievement. Semistructured interviews were conducted with 11 elementary general education teachers. Volunteers were recruited from schools having ELL populations of 30\% or more. Interview data were analyzed by using open and a priori codes and thematic analysis. The findings indicated that participants used familiar instructional strategies and consistently applied them for the whole class. Additionally, participants perceived ELLs' academic confidence and connecting concepts with their primary language as important to academic achievement. This study contributes to positive social change through a deeper understanding of the ELL instructional strategies that may benefit elementary teachers and stakeholders.
\end{abstract}

Keywords: English language learners, classroom instruction, instructional strategies, language instruction

\section{Introduction}

\subsection{Introduce the Problem}

There is a need to understand the current instructional strategies used by general education teachers when teaching English Language Learners (ELLs). ELLs are a fast-growing student population in the United States (U.S.) (National Center for Education Statistics, 2018). However, many teacher preparation programs do not provide adequate training on facilitating instruction for ELLs (de Araujo, Sakow, Smith \& Yeong, 2015; Zhang, 2017). This creates a gap in teacher training and meeting the real-world needs of these students. Although ELLs have specific teachers assigned to manage their needs with either in-class or pull-out sessions, the amount of time dedicated to each student is combined with other children and limited to certain days and times (Giles, 2020). This model leaves ELLs with the majority of their time within their general education classes with most of their support only from their teacher and peers (Giles, 2020). A deeper understanding of ELL instructional strategies used by general education teachers may benefit ELLs and the schools that support them.

A deeper understanding of teachers' perceptions of ELL strategies helps evaluate the current practice of teachers. Teachers' perceptions of the benefits of strategies are important. If teachers believe that the strategies are advantageous to students, they will be likely to apply the strategy consistently (Greenfield, 2016). It can be beneficial to 
administrators to understand which strategies teachers' value and provide insight into the application of appropriate, research-based strategies (Wissink \& Starks, 2019). Appropriate implementation of research-based strategies ensures that students receive the scaffolds they need to support their learning (Franco-Fuenmayor, Padròn \& Waxman, 2015). Research-based strategies support the learner with academic language and have a proven track record to increase student achievement (Master, Loab, Whitney, \& Wyckoff, 2016). A deeper understanding helps illuminate the current practices in the districts' classrooms.

The findings of this study have the potential to inform future trainings, which can be an effective way to support teachers and increase their competency to support ELLs. Teacher perceptions also aid in the understanding of which needs are prioritized for ELLs by the teachers and their reasoning behind it (Lachance, Honigsfeld, \& Harrell, 2019). Teacher training supports their ability to implement appropriate strategies (Lucero, 2015). This is beneficial to ELLs because it aids in the efforts to increase their academic success. Teacher training is an important tool to support the application of ELL appropriate strategies in the classroom. Murphy, Haller and Spiridakis (2019) found that teachers reported significant value in training to support the implementation of ELL specific strategies.

General education teachers spend the most amount of time with ELLs and need training to access the strategies to support their students. Training for teachers is important to support ELLs within the district. Johnson, Bolshakova, and Waldron (2016) found that professional development can increase the quality of lessons, increase student engagement and improve test scores for ELLs. The study's findings support training efforts for the district and teachers in the area of application of ELL strategies by providing insight into the current application of ELL strategies in mainstream classrooms. Bohon, Mckelvey, Rhodesa and Robnolt (2017) found that teachers can benefit from professional development on the application of ELL specific strategies, even if they have had previous training on ELLs. Continual professional development supports educators' performance. Roberts (2020) found that teachers and teacher trainers need support to identify applicable scaffolds for ELLs. This further substantiates the need for this study.

\subsection{Explore Importance of the Problem}

The research problem represents a gap in practice because it is uncertain how teachers in the local context are or are not applying appropriate, research-based ELL instructional strategies. Education researcher Marzano (2001) described research-based strategies as instructional practices based in research that support academic achievement. Research-based strategies are widely accepted as best practices for ELLs (Echevarria, Vogt, \& Short, 2012). The gap in practice is evidenced by the lead ESOL teacher, who stated that many of the teachers are not using research-based strategies in the classroom with fidelity. In addition, peer and administrator observations of the classrooms only provide a brief window into teachers' practices, which is not enough to understand the full application of ELL strategies, according to the teacher. This indicates a need for increased understanding about how general education teachers apply ELL instructional strategies and their perceptions of the support for ELLs.

\subsubsection{Literature Review to Support the Problem}

A broader view of the literature indicates a need for a deeper understanding of ELL instructional strategies that are used within mainstream classrooms. Research suggests that little is known about general education teachers' application of ELL instructional practices in the classroom and the perceived benefit of those practices. Rodriguez and Briceño (2018) found that, although some strategies are being implemented within the classroom for ELLs, they are not always implemented appropriately. Furthermore, Zhang et al. (2017) asserted that it was unclear how elementary mainstream teachers are implementing strategies for ELLs in the classroom. Although their findings contributed to an understanding of language strategies appropriate for elementary ELLs, there remains a gap in understanding of how instructional practices are actually applied in mainstream elementary classrooms. Lee (2020) established that elementary general education teachers struggle with meeting the needs of ELLs, and Brown and Endo (2017) found that teachers often confuse the needs of ELLs and use generic differentiation techniques that do not address ELL specific needs. Also, general education teachers tend to avoid instructional strategies that are intended primarily for ELLs. Researched-based strategies are difficult for elementary general education teachers to integrate within mainstream classrooms, which are often crowded with students who have many different needs (Capitelli et al., 2016). Teachers' practices often conform to their own perception of feasibility because they lack the training needed to facilitate the strategies (Hallman \& Meineke, 2016). This situation further validates the need for more understanding of ELL instructional strategies utilized within mainstream classrooms that are used by general education teachers and their perceptions of these practices.

Jimènez-Castellanos and Garcia (2017) found that general education teachers are not prepared to meet the needs of ELLs in the general education classroom. Additionally, Penner-Williams, Diaz, and Gonzales Worthen (2019) discovered that although some strategies for ELLs are implemented, not all strategies were implemented with fidelity 
or consistency. Teachers implemented some strategies but lack the time and training to adequately implement strategies specifically for ELLs. Song (2016) found that many teachers do not have the skills or training to implement the ELL specific strategies. Also, Coady, Harper, and de Jong (2016) found that new mainstream elementary teachers lacked the necessary skills to identify the needs of ELLs operating at different language development stages and to differentiate the content accordingly. This type of differentiation requires extra training that teacher preparation programs do not provide (Coady et al., 2016). Therefore, research indicates that there are inadequate practices employed within many mainstream United States elementary classrooms because of a lack of teacher training (Gottschalk, 2015; Song 2016).

Inadequate practices lead to reduced student performance. ELLs perform lower than their English-speaking peers in academic testing. By the time they reach high school, many ELLs are 30-40 points behind on state testing (Jiménez-Castellanos \& García, 2017). The lower scores could be due to ELLs having teachers who are not prepared for their needs, underfunding in their schools, or lack of programs and materials designed to meet their needs (Jiménez-Castellanos \& García, 2017). An exploration of the perceptions of elementary general education teachers on ELL specific strategies would be a benefit. Research on teachers' perceptions can provide insight into the gap between research-based strategies and current practices within the elementary general education classroom. Spees et al. (2016) described general education teachers as lacking the preparation to support ELLs effectively.

Many mainstream elementary teachers implement ELL strategies within the classroom based on their personal knowledge and training, not research-based pedagogy. Cervetti, Kulikowich, and Bravo (2015) described teachers' pedagogy as being a result of their experiences. Teachers' desire to provide an equitable learning experience is guided by their preferences and familiarity with the instructinal practices (Irby et al., 2018). Even veteran teachers find it difficult to use research-based practices to create learning environments for diverse learners (Cardimona, 2018). Teachers' lack of confidence in implementing strategies for these diverse learners often causes them to favor strategies based on feasibility (Andrei, Ellerbe, \& Cherner, 2015). Turkan and De Jong (2019) found that elementary teachers are aware that ELLs need different strategies; however, they are unclear of the value or ways to implement strategies effectively. It follows, therefore, that the quality of strategies used within the classroom may suffer because teachers are not incorporating research-based practices.

Researchers have investigated teachers' perceptions of their practice and found them valuable (Agcam \& Babanoglu, 2016; Bahreini \& Zamanian, 2017; Kiralp \& Bolkan, 2016; Tajeddin \& Adeh, 2016). However, the research is limited regarding teachers' perceptions of their own strategies for ELLs. Carley Rizzuto (2017) found that teachers' perceptions shaped their instructional practices. There is a need to understand the perceptions of teachers because research indicates that their perceptions influence how they implement instructional strategies (Lumbrears \& Rupley, 2019). If they perceive including ELL specific strategies as valuable, then it is more likely that they will include these strategies in their practice.

\subsection{Research Questions}

The researcher sought to explore general education teachers' reported application of ELL instructional strategies and their perception of the effectiveness of those strategies on ELL academic achievement. Mahalingappa, Hughes, and Polat (2018) found that many teachers struggled to understand research-based strategies to use within the classroom and would benefit from more support. Mahalingappa et al. also concluded that support with ELL strategies had a positive impact on teachers' self-efficacy. It would be beneficial to explore what reported strategies are used in the classroom and which of these are perceived as valuable by teachers. To understand the reported application of ELL strategies by elementary general educators, the researcher developed the following research questions (RQs):

RQ 1: What ELL instructional strategies do elementary general education teachers report applying in their classes?

RQ 2: From the perspective of elementary general education teachers, which ELL instructional strategies support ELL academic achievement?

\section{Method}

The purpose of this research study was to explore elementary general education teachers' reported application of ELL instructional strategies and their perception of how those strategies support ELL academic achievement. The research problem was is the lack of understanding of how elementary general education teachers apply instructional strategies for ELLs and which strategies they perceive support academic achievement. 


\subsection{Research Designs}

A basic qualitative methodological approach was used in this study. This approach was logically derived from the problem and RQs because both focus on teachers' perceptions of ELL specific instructional practices. Qualitative research is appropriate for exploring teachers' perceptions of ELL strategies and their perceived effectiveness (Merriam \& Tisdell, 2016) and collecting data on participants' perceptions (Creswell, 2015). For this study, the problem was the limited understanding of how elementary general education teachers apply instructional strategies for ELLs and which strategies they perceive support academic achievement. This approach is appropriate for investigating perceptions. The purpose of qualitative research was to identify common themes within teachers' perceptions. Themes help researchers understand and organize the data collected (Creswell, 2015). Thematic analysis supported my ability to investigate the phenomenon of teachers' perceptions.

\subsection{Participants}

This study had participation from 11 elementary general education teachers. The teachers had varied years of experience of teaching. Each teacher had at least two or more ELL students within their class, and many of the teachers had more than half of their students identified as ELLs. Teachers selected as participants of this study were mainstream general education teachers. This ensured that participants were familiar with the needs of ELLs and have experience using ELL specific strategies in the general education classroom. This provided the study with valuable insight into the application of ELL strategies in the mainstream classroom.

\subsection{Sampling Procedures}

The sampling strategy was purposeful sampling. Recruitment included participants who worked with ELLs within their classroom, which provided vital information to contribute to the current study's purpose because of participants' classroom demographics. Purposeful sampling refers to the researcher's selection of individuals who align with the needs of the study based on certain indicators or qualities (Creswell, 2015). In order to understand the perceptions of teachers on ELL-specific strategies, it was necessary to recruit teachers who teach ELLs for the data collection.

Eleven participants were an appropriate sample size for this study because it met the data saturation needs for this study. In-depth data was collected to still allow participants to maintain their uniqueness (Palinkas et al., 2017). This sample size $(n=11)$ is appropriate to investigate teachers' perceptions and their application of strategies that improved academic achievement for ELLS. Eleven participants met the sampling needs of this study because collection of in-depth perceptions to answer the RQs with enough data saturation to identify patterns was achieved.

\subsection{Data Collection}

Teacher interviews are the only data source to identifying teachers' perceptions for this study. A semistructured interview protocol that contained open-ended questions based on the constructs of the conceptual framework was used. Data collection for the study is appropriate for qualitative research because interviews are a typical qualitative data collection method (Merriam \& Tisdell, 2016). The RQs, designed to identify the perceptions of teachers about ELL specific strategies, lend themselves to the method of interviews.

\section{Results}

Creswell's (2015) steps for analyzing data to analyze the data collected from the 11 interviews was used. These steps include: (a) organize and prepare, (b) review, (c) code, (d) identify themes and (e) interpret.

\subsection{Categories and Themes}

Codes were merged into categories. Once the codes became clearer, it was easer to identify the categories of codes. Code was refined into categories by combining clusters of codes. For example, the codes connections, native language, and unstructured talk time were combined into the category of interactional supports. Categories organize the data further to create a clear distinction in the types of codes. Creating categories helped identify further connections between the codes (Creswell, 2015). Several categories were created which were later merged into larger categories. The categories found in this data set are: (a) instructional strategies, (b) culture-based supports, (c) interactional supports and (d) perceptions of strategies. The categories were analyzed for alignment with the RQs. A coding tabl was used to further merge the categories into themes which helps build my interpretation of the findings.

Then, the codes were reviewed and refined to create broader categories. Themes were created by refining and collapsing categories that were similar. Priori and emergent codes were developed and then categories were identified, such as instructional strategies and interactional supports. Afterwards, the categories were used to identify themes and 
combined categories to expand to themes that answered the RQs (Creswell, 2015). From the categories, five themes were identified.

\subsection{Theme Development}

A combination of a priori and emergent coding were used. After reviewing the frequency and commonalities of the initial codes in the first coding table, a priori codes, emergent codes, categories, themes and interview excerpts were identified. The categories were based on the type of code. The categories were merged to create themes that conceptualize the findings of this study. Condensing categories supported building a clearer picture of the data (Creswell, 2015). Braun et al. (2019) suggested that having a smaller number of themes is ideal to keep the finding clear. The themes were applied to building the findings of this study by aligning each theme to corresponding the RQ (Merriam, 2009). Table 1 shows the alignment.

Table 1. Findings from the Research Questions

\begin{tabular}{|c|c|}
\hline \multicolumn{2}{|c|}{ Findings for RQ 1} \\
\hline Theme & Number of participants who reported \\
\hline $\begin{array}{l}\text { ELL strategies were referenced as best } \\
\text { practices and applied for all students. }\end{array}$ & 11 \\
\hline $\begin{array}{l}\text { Teachers use familiar and varied } \\
\text { instructional strategies to meet ELLs' } \\
\text { academic needs. }\end{array}$ & 11 \\
\hline \multicolumn{2}{|c|}{ Findings for RQ 2} \\
\hline Theme & Number of participants who reported \\
\hline $\begin{array}{l}\text { Elementary general education teachers } \\
\text { perceive student confidence as necessary for } \\
\text { academic gains and prefer strategies that } \\
\text { encourage socio-emotional development. }\end{array}$ & 7 \\
\hline $\begin{array}{l}\text { Building connections for ELLs is important } \\
\text { for their conceptual understanding. }\end{array}$ & 6 \\
\hline \multicolumn{2}{|c|}{ Emergent theme } \\
\hline Theme & Number of participants who reported \\
\hline $\begin{array}{l}\text { Teachers want purposeful and relevant } \\
\text { professional development to meet ELLs' } \\
\text { various academic needs. }\end{array}$ & 6 \\
\hline
\end{tabular}

\subsection{Research Question 1 Findings}

Research Question 1 was, What ELL instructional strategies do elementary general education teachers report applying in their classes? Themes one and two address this question and provide insight into the instructional strategies applied in elementary general education classrooms. Themes three and four address RQ 2. Theme 5 does not address either RQ; it emerged from the interview data. The first theme was that participants referenced ELL strategies as best practices and applied for all students. The second theme was that teachers use varied and familiar instructional strategies to meet ELLs' academic needs use varied and familiar instructional strategies to meet ELLs' academic needs.

Theme 1: ELL-Specific Strategies Were Referred to as Best Practices and Were Applied for All Students (Even Non-ELLs). The first theme that emerged from the data was that ELL specific strategies such as visuals, sentence starters, hands on experiences, and word banks were applied for the whole group and regarded as best practices for all students. All 11 participants stated that they apply some ELL specific strategies and apply it for the whole group. Participants within this study applied these strategies as universal scaffolds in teaching and not as a particular ELL strategy. Thus, applying ELL strategies for the whole class was perceived as beneficial for student engagement and achievement. This aligns with previous research and the conceptual framework concepts of interactions. Tellèz and Manthey (2015) inferred that teachers preferred whole group strategies for ELLs. Feasibility and reaching all students efficiently are a concern for educators and whole group strategies allow teachers to reach more students at one time (Nagaro, Hooks \& Frazer, 2016). Samalot-Rivera, Treadwell, and Sato (2017) claimed that teacher implementation of ELL instructional strategies for the whole class is beneficial. It also supports Krashan's theory of the use of teacher to student interactions to develop language (Lowen \& Sato, 2018). Teachers' concerns for 
feasibility is further validated by Coady et al. (2020) who emphasized teacher's preference for whole group strategies to support students rather than differentiating for specific groups.

Theme 2: Teachers Used Various Familiar Instructional Strategies to Meet ELLs' Academic Needs. Teachers chose strategies based on their preference and familiarity rather than strategies specific for ELLs. All 11 general, education teachers used some strategies within the classroom. Table 2 displays the various strategies reported by participants. Teachers stated that various strategies worked together to support ELL academic achievement and some strategies at the same time, during the same lesson. For example, all participants reported using visuals to help students understand the directions or the vocabulary, however if the visual was not enough, zero participants report trying a new strategy. Instead, participants reported using the same strategy in a different way. Participants reported using vocabulary strategies, modeling, scaffolding and small groups often within the same lesson. This aligns with the conceptual framework construct of culture supporting language acquisitions. The classroom culture of familiar strategies support students' language development (Badrkhani, 2019). Participants described various strategies that they used for both in-person and virtual lessons to support ELLs, such as visuals, sentence frames, frontloading vocabulary, videos and building connections with prior knowledge as frequently used strategies. Although teachers use different strategies to support ELLs, teachers preferred to use the same strategies and modify the strategy.

This theme aligns with what one would expect from the findings in the literature review. Participants prefer to use various but familiar strategies and need familiarity with more strategies to implement. According to Hilliker and Laletina, (2019) teachers apply strategies that they are familiar with in their instructional practice and do not intentionally seek other strategies. Researchers go on to say that teachers use similar strategies consistently and time is a hindrance to acquiring new strategies. Murphy and Torff (2018) asserted that teachers prefer to use feasible strategies and modify the curriculum to support ELLs. Most participants applied many strategies that were not specific for ELLs and preferred strategies based on their feasibility with English-speaking students. Mahalingappa et al. (2018) found that teachers lacked consistent practices necessary to support ELLs. According to Krashan's second language acquisition theory (1981), students need ample opportunities to practice with the new language and support to gain the new language. This theme informs RQ 1 because it identifies that teachers used strategies that they found familiar rather than basing strategies on specific students' needs.

Table 2. Frequency Table

\begin{tabular}{lc}
\hline \multicolumn{1}{c}{ Strategy } & Strategies Reported by Each Participant \\
\hline Realia & Number of participants who reported \\
Visuals & 4 \\
Build background & 11 \\
Sentence frames & 9 \\
Scaffolding & 9 \\
Peer pairs & 6 \\
Vocabulary instruction & 6 \\
Unstructured talking & 3 \\
Modeling & 6 \\
Reduce Workload & 11 \\
Songs & 4 \\
Translation & 3 \\
\hline
\end{tabular}

\subsection{Research Question 2 Findings}

To answer RQ 2, the data was analyzed for patterns and using sociocultural and language acquisitions theory constructs. RQ 2 asked, "from the perspective of elementary general education teachers, which ELL instructional strategies support ELL academic achievement?" The analysis indicated (a) that elementary teachers perceive that when they encourage student self-confidence it can be beneficial to ELL academic gains, and that (b) building connections to the content and their native language for ELLs is important for their conceptual understanding and language acquisition. This indicated that there was a consensus that specific strategies of building connections and confidence were important for ELLs and further training was necessary to effectively support ELLs through those strategies.

Theme 3: Elementary Teachers Perceive Student Confidence as Necessary for Academic Gains. Elementary 
teachers perceived student confidence as a prerequisite to achievement. Seven participants viewed higher confidence as an indicator of readiness for academic risk taking. Nine out of the 11 participants shared that confidence is important. Student confidence was perceived as an indicator of the effectiveness of the instructional strategies and increased readiness for language acquisition.

This theme aligns with the conceptual framework construct of classroom culture that builds confidence. It is used as a support for language development (Castrillón, 2017). Murphy (2018) asserted that language acquisition is interconnected with confidence. High confidence then plays a critical role in ELLs desire and motivation to take academic risks. This is further evidenced by Ingraham and Nuttall (2018), who discussed the connection between ELLs confidence and risk taking as important factors in academic gains. Researchers go on to (Ingraham \& Nuttall, 2018) indicate that openness and encouragement from the school and teachers have allowed students to feel more confident and take more risks, which led to more academic gains. Participants within this study also asserted that openness and encouragement increased ELL engagement and performance. Spencer and Balmer (2020) agreed that self-confidence is an important area to address for ELLs. Promoting student self-confidence increases the engagement with academic language and class content. This indicates that increased ELL self-confidence is meaningful to academic achievement.

Theme 4: Building Connections to ELLs' Native Language Is Important for Their Conceptual Understanding and Language Acquisition. The fourth theme from this data is building language connections between their first language and second language is important for ELLs' conceptual understanding and language acquisition. This finding is supported by the conceptual framework of this study which asserts that people learn language through their need to interact with their environment. Nine out of the 11 participants indicated that building connections from their first language supported students' ability to transfer to the new language. Specifically, all nine participants mentioned that translating and allowing students to speak or hear the prompts in their native language was beneficial for students' academic performance. Teachers were using students' ability to make connections with their primary language to support teaching the content in the new language. Teachers viewed creating first to second language connections and opportunities to work with their first language as positive supports for language acquisition.

This theme aligns with the guiding principles of teaching English to students of other languages, in that building on the first language is beneficial to support attainment of the new language (Cummins, 2011). This also directly relates with Krashan's second language acquisition theory (1981) in that second language is built on the native language and develops based on the need to interact with one's environment. Building connections to student's primary language allows students the opportunity to transfer knowledge to their new language. Mitterer, Eger, and Reinisch (2020) emphasized encouraging the primary language of a student to increase second language acquisition. Participants in the study viewed encouraging students to use their primary or first language as beneficial for their academic and language gains.

\section{Emergent Theme}

Theme 5 emerged from that data and describes teachers' perception of the value of professional development as an opportunity to learn and engage in creating better instructional practices. This theme does not address either RQ. However, this indicated some varied perceptions of training. Five teachers want a review training, and three teachers want full training. This aligns with the research in that teachers have varying professional development needs based on their previous experiences. Asmari (2016) stated that continuous professional development is beneficial to teachers. This allows teachers to get more information on the professional development concepts over the course of an extended period. Parrash et al. (2020) asserted that there is a level of various in the desires of teachers on professional development. Tantawy (2020) claimed that teachers have different professional development needs. This aligns with the research in that professional development is helpful to the instructional practice of teachers and teachers have different professional development needs (Bana \& Cranmore, 2019; Horan \& Merrigan, 2019). Teachers are able to gain valuable information from professional develop and is beneficial to their practice.

Theme 5: Teachers Want Purposeful and Relevant Professional Development to Meet ELLs' Academic Needs. Participants had positive views on professional development as an opportunity to learn different instructional practices to use to best support students. Six out of the 11 participants expressed a need for more relevant professional development on ELL strategies. Two participants wanted full training and four participants wanted a review training. Participant 2, 3, 4, 7, and 9 were all SIOP certified through the district. They referred to this as a positive experience to enhance their practice. This brought to attention the need for training that reviewed some SIOP components and connected ESOL teachers with general education teachers for an opportunity to collaborate would be beneficial and received well by teachers. 
This theme aligns with the literature in that professional development is considered an essential support to educators. Professional development with all stakeholders can increase teacher buy in and support instructional practices. Avci, O'Dwyer and Lawson (2020) found that professional development on a topic can provide teachers with resources and skills to support instructional best practices. Additionally, the facilitators of the training need to position the content in a way to increase teacher buy-in and implementation (Roberts, 2020). Furthermore, professional development can support teachers to confidently apply learned strategies (Rutherford-Quach, Kuo, \& Hsieh, 2018). Professional development is an important tool to support educators and stakeholders.

\section{Discussion}

The purpose of this research was to investigate the perceptions of elementary general education teachers on ELL strategies and their perceived effectiveness. The gap in instructional practices was illustrated in the literature review and this gap emphasized the need to understand teachers' application of ELL strategies and perceptions of the benefits of these strategies.

Alternatives to this research study could include an online training cohort. Online training would be offered over the course of several weeks and could be credit-bearing. The online training course allows teachers to access their learning at their own convivence and supports their need to have choice over their learning (Elliot, 2020). However, the synchronous opportunities would be limited because the format would be self-paced. Teachers' opportunities to collaborate in real-time would be limited (Fiel, Lawless, \& Brown, 2018). Still, online training can be as effective as in-person professional development (Philipsen, Tondeur, McKenney, \& Zhu, 2019).

Another option would be to conduct a Professional Learning Community (PLC) to study best practices through a book on best practices for ELLs. Book studies are effective in supporting educators in collaborating with one another within the PLC (Cameli, 2020). A limitation of this method would be the lack of diverse information presented to support various needs within the PLC and the loss of directed learning opportunities (Korthagen, 2017). Book studies are also limited in their learning capacity because they focus on one text (Blanton, Broemmel, \& Rigell, 2020). Yet, a book study PD would be another way to address the problem.

The influences for positive social change from this research study include understanding of elementary general education teachers' classroom practices and perceptions of those practices. It is vital to recognize the application of student-based supports within the classroom to truly understand the gap in achievement between ELLs and English-speaking students. ELLs are one of the fastest growing populations within the United States (National Center for Education Statistics, 2015). It is critical to understand the practices that best support ELLs in the mainstream classroom. This study's findings illuminated the practices and preferences of elementary general education teachers. The results can support district leaders in catering training to provide for the gaps in teacher knowledge (Hestness, Ketelhut, McGinnis, \& Plane, 2018). It can also further efforts to facilitate collaboration between all stakeholders and address paraeducator training needs (Song et al., 2018). Additionally, teacher preparation programs may gain understanding regarding the importance of including ELL focused courses to address the changing educational landscape (Erarslan, 2020).

For this study, elementary general education teachers and their perceptions and application of ELL specific strategies were reviewed. Five themes emerged from this study. Participants agreed that the prefer to use familiar and varied ELL specific strategies. Some participants discussed using the strategy even if it did not work the first time as well as applying various strategies at the same time. Another theme that emerged from the data was that teachers prefer to implement strategies whole group rather than for specific groups of students. This is substantiated by the literature in that teachers choose strategies based on feasibility (Knight \& Gilpatrick, 2019). This further elevates the need for quality professional development that address how to appropriately address ELLs' needs in the mainstream elementary classroom (Edwards, 2016). Future research could expand to understanding the application and perceptions of ELL strategies in the middle and high school levels. Expanding the research population can increase the perspectives on ELL specific strategies and provide insight on best practices for ELLs across different age groups. This would allow a broader picture of the instructional practices for all K-12 ELLs. Additionally, future research can also investigate the perceptions of ESOL and special education teachers on the efforts and implementation of strategies for dually identified students. Further research can identify how to support this specific population (Zetin, 2011; Barwasser, Knaak \& Grünke, 2020). These topics can add to overall body of research supporting best practices for ELLs in the classroom. Expanding the population of teachers would be the next step based on this research because this study had a narrow focus with only the perceptions of elementary general education teachers. An expanded teacher population would provide a broader perspective of teachers on ELL strategies. These topics can add to overall body of research 
supporting best practices for ELLs in the classroom.

In conclusion, this reseach study has provided the opportunity to reflect on elementary general education teachers' practices and their perceptions and how those influence students' experiences. Students' ability to perform to their best ability is influenced by teachers' practices. Elementary teachers need adequate training to provide strategies that support student learning. Although the data from my study indicated that teachers apply strategies for ELLs, data from the literature review and the current U.S. trend of the achievement gap between ELLs and native speakers reflects on the lack of teacher understanding on scaffolds and appropriate strategies to support ELL students. In addition, the data from this study was collected from was collected from teachers who has received some trainings on ELLs and found it beneficial in their practice. This further implicated that teacher training is an essential component to teacher and student growth. Teachers are required to support diverse student populations and they need support to adequately provide for students.

\section{References}

Andrei, E., Ellerbe, M., \& Cherner, T. (2015). "The Text Opened My Eyes": A Book Club on Teaching Writing to ELLs. TESL-EJ, 19(3).

Avci, Z., O’ Dwyuer, L., \& Lawson, J. (2020). Designing effective professional development for the technology integration in schools. Journal of Computer Assisted Learning, 36(2), 160-177. https://doi.org/10.1111/jcal.12394

Badrkhani, P. (2019). Storytelling in early childhood: enriching language, literacy and classroom culture. Education 3-13, 47(6), 775-777. https://doi.org/10.1080/03004279

Bana, W., \& Cranmore, J. (2019). Elementary teacher perceptions of professional development on the neuroscience of learning. Mid-Western Education Researcher, 31(3), 333-347.

Blanton, B. S., Broemmel, A. D., \& Rigell, A. (2020). Speaking volumes: professional development through book studies. American Educational Research Journal, 57(3), 1014-1044.

Brown, C. L., \& Endo, R. (2017). The challenges of differentiating instruction for ELLs: an analysis of content-area lesson plans produced by pre-service language arts and social studies teachers. Teacher Education \& Practice, $30(3), 372-385$.

Cardimona, K. (2018). Differentiating mathematics instruction for secondary-level English Language Learners in the mainstream classroom. TESOL Journal, 9(1), 17-57. https://doi.org/10.1002/tesj.303

Capitelli, S., Hooper, P., Rankin, L., Austin, M., \& Caven, G. (2016). Understanding the development of a hybrid practice of inquiry-based science instruction and language development: A case study of one teacher's journey through reflections on classroom practice. Journal of Science Teacher Education, 27, 283-302. https://doi.org/10.1007/s10972-016-9460-9

Carley Rizzuto, K. (2017). Teachers' perceptions of ELL students: do their attitudes shape their instruction? Teacher Educator, 52(3), 182-202. https://doi.org/10.1080/08878730.2017.1296912

Cameli, S. (2020). A different kind of book club: choice and voice fuel learning in Hawaii's teacher leader academy. Learning Professional, 41(1), 48-51.

Castrillón, L. J. (2017). The effects of Vygotsky's sociocultural theory on second language acquisition and language Input. ESPIRAL: Revista De Docencia E Investigación, 7(1), 91-102. https://doi.org/10.15332/erdi.v7i1.1780

Cervetti, G. N., Kulikowich, J. M., \& Bravo, M. A. (2015). The effects of educative curriculum materials on teachers' use of instructional strategies for English language learners in science and on student learning. Contemporary Educational Psychology, 40, 86-98. https://doi.org/10.1016/j.cedpsych.2014.10.005

Creswell, J. W. (2015). Educational research: Planning, conducting, and evaluating quantitative and qualitative research. Boston: Pearson.

Coady, M., Harper, C., \& De Jong, E. (2016). Aiming for equality: Preparing mainstream teachers for inclusion or inclusive classrooms? Tesol Quarterly, 50(2), 340-368, https://doi.org/10.1080/004005841.2013.770326

Coady, M., Miller, M., Jing, Z., Heffington, D., Lopez, M., Olszewska, A., \& Ankeny, R. (2020). Can English Learner effectiveness be observed? Validation of an EL-Modified framework for teaching. TESOL Quarterly, 54(1), 173-200. https://doi.org/1002/tesq.544 
Cummins, J. (2013). BICS and CALP. In P. Robinson (Ed.), The Routledge encyclopedia of second language acquisition (pp. 65-66). New York: Routledge

De Araujo, Z., Yeong I, J., Smith, E., \& Sakow, M. (2015). Preservice teachers' strategies to support English Learners. Education Conference Presentations, Posters and Proceedings, 4. Retrieved from https://lib.dr.iastate.edu/edu_conf/4

Erarslan, A. (2020). The voices of English language teachers regarding professional development: a third space activity for in-service English language teachers. International Online Journal of Education \& Teaching, 7(3), 1077-1090.

Fiel, J., Lawless, K. A., \& Brown, S. W. (2018). Timing matters: approaches for measuring and visualizing behaviors of timing and spacing of work in self-paced online teacher professional development courses. Journal of Learning Analytics, 5(1), 25-40.

Franco-Fuenmayor, S., Padrón, Y., \& Waxman, H. (2015). Investigating Bilingual/ESL teachers' knowledge and professional development opportunities in a large suburban school district in Texas. Bilingual Research Journal, 38(3), 336-352. https://doi.org/10.1080/15235882.2015.1091049

Giles, A., \& Yazan, B. (2020). You're not an island": a middle grades language arts teacher's changed perceptions in ESL and content teachers. Collaboration. Research in Middle Level Education Online, 43(3), 1-15. https://doi.org/10.1080/19404476.2020.1724045

Gottschalk, B. (2016). Ten (Usually Wrong) Ideas about ELLs. Educational Leadership, 73(5), 62-64.

Greenfield, R. A. (2016). Educating linguistically diverse students: a mixed methods study of elementary teachers: coursework, attitudes, and practice. Current Issues in Education, 19(1). Retrieved from https://cie.asu.edu/ojs/index.php/cieatasu/article/view/1530

Hestness, E., Ketelhut, D. J., McGinnis, J. R., \& Plane, J. (2018). Professional knowledge building within an elementary teacher professional development experience on computational thinking in science education. Journal of Technology and Teacher Education, 26(3), 411-435.

Horan, M., \& Merrigan, C. (2019) Teachers' perceptions of the effect of professional development on their efficacy to teach pupils with ASD in special classes. Reach, 32(1), 34-49.

Ingraham, N., \& Nuttall, S. (2016). The story of an arts integration school on English-language-learner development: A qualitative study of collaboration, integrity, and confidence. International Journal of Education \& the Arts, 17(28). Retrieved from http://www.ijea.org/v17n28/

Jiménez-Castellanos, O., \& García, D. (2017). School expenditures and academic achievement differences between high-ELL-performing and low-ELL-performing high schools. Bilingual Research Journal, 40(3), 318-330. https://doi.org/10.1080/15235882.2017.1342717

Johnson, C. C., Bolshakova, V. L. J., \& Waldron, T. (2016). When good intentions and reality meet: Large-scale reform of science teaching in urban schools with predominantly Latino ELL students. Urban Education, 51(5), 476-513. https://doi.org/10.1177\%2F0042085914543114

Korthagen, F. (2017). Inconvenient truths about teacher earning: towards professional development 3.0. Teachers and Teaching, 23(4), 387- 405, https://doi.org/10.1080/13540602.2016.1211523

Krashen, S. D. (1981). Second language acquisition and second language learning. Pergamon Press Inc., Oxford.

Lachance, J. R., Honigsfeld, A., \& Harrell, G. (2019). Equal educational opportunity for English learners: ESL teachers' conceptualizations on the importance of academic language. TESOL Journal, 10(2), N.PAG. https://doi.org/10.1002/tesj.415

Lee, S. (2020). Analysis of the effect of school organizational culture and professional learning communities on $\begin{array}{lllll}\text { teacher efficacy. Integration of } & \text { Education, } & 24(2), & 206-217 .\end{array}$ https://doi.org/10.15507/1991-9468.099.024.202002.206-217

Long, M. H. (1983). Does second language instruction make a difference? a review of research. TESOL Quarterly, 17, 359-382. https://doi-org.ezp.waldenulibrary.org/10.2307/3586253

Lucero, A. (2015). Dual language teachers' use of conventional, environmental, and personal resources to support academic language development. Bilingual Research Journal, 38(1), 107-123. https://doi.org/10.1080/15235882.2015.1017028 
Lumbrears, R., Jr, \& Rupley, W. H. (2019). Educational experiences of ELL educators: Searching for instructional insights to promote ELL students' learning. Educational Research for Policy and Practice, 18(1), 17-38. https://doi.org/10.1007/s10671-017-9225-z

Mahalingappa, L., Hughes, E. M., \& Polat, N. (2018). Developing preservice teachers' self-efficacy and knowledge through online experiences with English language learners. Language \& Education, 32(2), 127-146. https://doi.org/10.1080/09500782.2017.1417996

Master, B., Loeb, S., Whitney, C., \& Wyckoff, J. (2016). Identifying differentially effective teachers of English Language Learners. Elementary School Journal, 117(2), 261-284. https://doi.org/10.1086/688871

Merriam, S. B., \& Tisdell, E. J. (2016). Qualitative Research: A guide to design and implementation. San Francisco: Jossey-Bass.

Murphy, A., Haller E., \& Spiridakis, J. (2019). Teachers' perceptions of a mentoring cohort model in a program leading to certification to teach English language learners. Mentoring \& Tutoring: Partnership in Learning, 27(3), 295-316. https://doi.org/10.1080/13611267.2019.1630997

Murphy, A. F., \& Torff, B. (2019, January). Teachers' beliefs about rigor of curriculum for English language learners. In the Educational Forum, 83(1), 90-101. Routledge.

National Center for Education Statistics. (2018, April). English Language Learners in Public Schools. Retrieved January, 2019 from https://nces.ed.gov/programs/coe/indicator_cgf.asp

Penner-Williams, J., Diaz, E., \& Worthen, D. (2017). PLCs: Key PD components in learning transfer for teachers of English learners. Teaching and Teacher Education, 65, 215-229. https://doi.org/10.1016/j.tate.2017.03.014

Philipsen, B., Tondeur, J., McKenney, S., \& Zhu, C. (2019). Supporting teacher reflection during online professional development: a logic modelling approach. Technology, pedagogy and education, 28(2), 237-253.

Roberts, S. (2020) Important for all: positioning English Language Learners in mathematics professional development, The Teacher Educator, 55(1), 107-128. https://doi.org/10.1080/08878730.2019.1686557

Rodriguez, M. C., \& Briceño, A. (2018). Sentence stems that support reading comprehension. Reading Teacher, 72(3), 398-402. https://doi.org/10.1002/trtr.1705

Samalot-Rivera, A., Treadwell, S., \& Sato, T. (2018). Instructional strategies to consider when teaching Hispanic English-Language Learners in physical education. Strategies, 31(2), 26-30. https://doi.org/10.1080/08924562.2017.1418691

Spees, L., Potochnick, S., \& Perreira, K. (2016). The academic achievement of Limited English Proficient (LEP) youth in new and established immigrant states: lessons from the National Assessment of Educational Progress (NAEP). Education Policy Analysis Archives, 24(98/99), 1-31. https://doi.org/10.14507/epaa.24.2130

Spencer, K., \& Balmer, S., (2020). A pilot study: magic tricks in the ELL classroom increasing verbal communication initiative and self-efficacy. English Language Teaching and Linguistics Studies, 2(1), 11-32. https://doi.org/10.22158/eltls.v2n1p11

Song, K. H. (2016). Systematic professional development training and its impact on teachers' attitudes toward ELLs: SIOP and guided coaching. TESOL Journal, 7(4), 767-799. https://doi.org/10.1002/tesj.240

Turkan, S., \& de Jong, E. J. (2019). An exploration of preservice teachers' reasoning about teaching mathematics to English Language Learners. Teacher Education Quarterly, 45(2), 37-60.

Trevino Calderon, C., \& Zamora, E. (2014). Factors effecting the implementation of sheltered instruction observation protocols for English language learners. National Forum of Educational Administration \& Supervision Journal, 31(3), 20-32.

Vygotsky, L. S. (1978). Mind in society: The development of higher psychological processes. Cambridge, Massachusetts: Harvard University Press.

Zhang, J., \& Pelttari, C. (2015). Exploring the emotions and needs of English language learners: facilitating pre-service and in-service teachers' recognition of the tasks facing language learners. Journal of Multilingual \& Multicultural Development, 35(2), 179-194. https://doi.org/10.1080/01434632.2013.822505

Zhang, Y. (2017). Supporting English Language Learners in Social Studies: Language-focused Strategies, The Social Studies, 108(5), 204-209. https://doi.org/10.1080/00377996.2017.1354808 


\section{Copyrights}

Copyright for this article is retained by the author(s), with first publication rights granted to the journal.

This is an open-access article distributed under the terms and conditions of the Creative Commons Attribution license (http://creativecommons.org/licenses/by/4.0/). 